\title{
Estigma e saúde mental na atenção básica: lacunas na formação médica podem interferir no acesso à saúde?
}

\section{| ${ }^{1}$ Vinícius Batista Vieira, ${ }^{2}$ Pedro Gabriel Godinho Delgado |}

Resumo: Este artigo tem como objetivo identificar competências médicas marcadas pelo estigma contra pessoas com transtornos mentais, analisando, a partir do conceito de habitus de Pierre Bourdieu, a interferência da formação médica no pensamento e na ação dos médicos da atenção básica para a condução de casos de pessoas com esses transtornos. Utilizou-se o recurso metodológico da observação participante e uma aula aplicada por um psiquiatra para médicos da atenção básica em atividade de matriciamento. Descrevemos a estratégia pedagógica desenvolvida que, quando analisada, foi capaz de demonstrar estigmas nas competências de médicos com potencial consequência negativa no atendimento dos usuários, sendo identificados generalizaçóes, reducionismos, desesperança e outros sentimentos negativos associados com barreiras de acesso ao cuidado.

Palavras-chave: Estigma social e saúde mental, saúde mental na atenção primária, antropologia médica, educação médica, atenção primária à saúde.

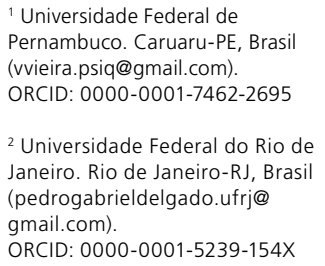

${ }^{1}$ Universidade Federal de Pernambuco. Caruaru-PE, Brasil (vvieira.psiq@gmail.com). ORCID: 0000-0001-7462-2695

${ }^{2}$ Universidade Federal do Rio de Janeiro. Rio de Janeiro-RJ, Brasil (pedrogabrieldelgado.ufrj@ gmail.com). ORCID: 0000-0001-5239-154X

Recebido em: 30/07/2020 Aprovado em: 19/04/2021 Revisado em: 09/10/2021 


\section{Introdução}

O estigma contra pessoas com transtornos mentais merece atenção de trabalhadores, gestores, preceptores e docentes engajados na atenção psicossocial e na atenção básica à saúde, uma vez que se evidencia na literatura como barreira de acesso a diversos serviços de saúde, inclusive atenção primária (NUNES; TORRENTE, 2009; RÉZIO et al, 2015; THORNICROFT, 2006).

Thornicroft (2006) aponta algumas estratégias educativas capazes de modificar as atuaçóes de profissionais de saúde de modo a minimizar o estigma, destacando a potencialidade do processo de aprendizagem para enfrentar esse problema.

Este trabalho pretende levantar reflexóes para a formação médica a respeito do estigma, a partir de estudo qualitativo, especialmente a observação de aula aplicada por um psiquiatra para médicos da atenção básica em uma atividade de matriciamento. Este artigo é fruto de pesquisa para o Mestrado Profissional em Atenção Psicossocial do IPUB/UFRJ, que partiu do interesse em compreender como a formação médica interfere no estigma relacionado ao transtorno mental, e quais aspectos do tornar-se médico têm relações com a estigmatização e consequente barreira de acesso das pessoas.

Madel Luz (2012) analisa o percurso histórico do pensamento médico ao lado do percurso epistemológico das ciências naturais desde o século XVI e o caminho que levou a uma visão do corpo humano como máquina ultra-compartimentada, exigindo disciplinas especializadas para o aprofundamento máximo do conhecimento particular de cada compartimento. Esse pensamento foi traduzido e concretizado no currículo médico pelo relatório Flexner (FLEXNER, 1910), ainda base hegemônica para o ensino médico e para o cuidado com ênfase na biomedicina, na superespecialização e na fragmentação.

A literatura discute diversas propostas de intervençōes curriculares que formem médicos com olhar humanístico e holístico (MOURA et al., 2020), mas ainda encontram dificuldades de efetivação. No Brasil, as atuais Diretrizes Nacionais para o Currículo de Medicina - DCN (Brasil, 2014), decretadas dentro de um conjunto de outras medidas para melhoria da atenção à saúde no país (BRASIL, 2013), tendem a tensionar o redirecionamento da formação de egressos com responsabilidade social, compromisso com defesa da cidadania, da dignidade humana e da saúde integral do ser humano, compreendendo como transversal a determinação social do processo saúde-doença. 
Isso amplia o escopo da atuação médica além do ato de diagnosticar doenças e tratá-las, havendo a exigência da aquisição de outras competências, do campo das atitudes, como a competência cultural, ou seja, competência para atuar diante da diversidade de pessoas e comunidades com culturas diferentes, para qualificar o atendimento a todas as pessoas (KIRMAYER, 2012).

O objetivo deste trabalho foi identificar competências médicas marcadas pelo estigma, analisando, a partir do conceito de habitus de Pierre Bourdieu (2007), a interferência da formação médica no pensamento e na ação dos médicos da atenção básica para a condução de casos de pessoas com transtornos mentais. O trabalho se insere no campo da antropologia em saúde, utilizando o recurso metodológico da observação participante.

\section{Aspectos Metodológicos}

Este trabalho consiste na análise de dados obtidos a partir da observação de uma estratégia educativa estruturada na forma de aula com método ativo de ensino para médicos do Programa Mais Médicos (PMM) do Ministério da Saúde (BRASIL, 2013).

A contextualização do campo de pesquisa é fundamental para compreender os passos do trabalho, que teve como cenário atividades de matriciamento entre uma equipe de Centro de Atenção Psicossocial (CAPS) e equipes da Estratégia de Saúde da Família (ESF). Como etapa do matriciamento, uma aula foi aplicada para parte da amostra, sendo a fonte dos dados sobre as competências pedagógicas de médicos para o atendimento a pessoas com transtornos mentais.

\section{$O$ contexto da pesquisa}

A pesquisa nasceu a partir de observaçóes da prática assistencial na Rede de Atenção Psicossocial de um município nordestino de região metropolitana pelo pesquisador principal, no papel de psiquiatra assistente de um CAPS II (com atuação em matriciamento).

O município é peculiar em sua geopolítica, agregando características rurais aos problemas da urbanização, devido ao rápido crescimento populacional decorrente da instalaçáo de um grande polo industrial (MATTOSO, 2013). O IDH era considerado muito baixo $(0,457)$ em 2000, passando em 2010 a pontuar 0,619 (médio). Esse índice ainda está abaixo de outras cidades da região, ainda mais se for considerado seu Produto Interno Bruto (PIB) (BRASIL, 2010). 
O território extenso e as dificuldades de acesso à rede de saúde elevam a importância da atenção básica no cuidado às pessoas que náo conseguem se deslocar de localidades mais distantes; por isso, são comuns casos de pessoas com transtornos mentais graves que não chegam aos especialistas em saúde mental, sendo acompanhados pelas ESF com apoio do CAPS.

Dificuldades como o acesso difícil às várias localidades rurais, escassez de serviços próprios em diversos setores, baixos índices de saneamento básico e educação precária da população foram somados ao aumento da demanda populacional e aos problemas de centros urbanos, como a violência (MATTOSO, 2013). Foram 47,77 homicídios por 100.000 habitantes em Ipojuca em 2013, enquanto a média nacional, no mesmo ano, foi de 28,55 (IPEA, 2013).

Todo esse cenário aparece nas falas de médicos das equipes de saúde da família quando em atividades de matriciamento. A aproximação dos médicos da realidade local aparentemente elevou a importância das condições sociais para o ato médico, tornando sua atuação mais complexa. Como clínico da atenção psicossocial, o pesquisador se aproximou da realidade dos territórios através do matriciamento e da aproximação com as equipes de saúde da família.

A seguir, serão abordados os aspectos epistemológicos e metodológicos da pesquisa.

\section{O Conceito de Habitus}

O conceito de habitus é amplo e bastante discutido nas ciências sociais. Aqui, apresentaremos alguns aspectos do conceito úteis a esta pesquisa, seguindo a formulação de Pierre Bourdieu.

$\mathrm{Na}$ direção do cuidado à saúde sem discriminação, a formação deve estar apta a pôr em xeque concepçóes do senso comum acerca dos transtornos mentais e o consumo de drogas. Pode-se afirmar que esse "senso comum" faz parte do que Bourdieu chama de habitus. Para ele, habitus é o conjunto de esquemas inconscientes que dirigem nossos pontos de vistas e açôes (BOURDIEU, 2007). Esses esquemas são construídos historicamente, tendo relação com as diferentes culturas e com as posiçóes de classe, de modo que pessoas da mesma cultura e classe compartilham habitus relacionado ao grupo a que pertencem. Esses esquemas condicionam as açóes das pessoas e são, em via contrária, condicionados pelas experiências.

O habitus tem relação com as posiçôes sociais ocupadas, determinando estilos de vida, é "estrutura estruturante que organiza as práticas e a percepção das práticas, é 
também estrutura estruturada: o princípio de divisão em classes lógicas que organiza a percepção do mundo social é, por sua vez, o produto da incorporação da divisão em classes sociais" (BOURDIEU, 2007, p.164).

Esse conceito interessa a este estudo justamente pelo fato de admitir que o habitus se constitui em um conjunto de códigos estruturados e estruturantes que são comuns aos grupos classificáveis socialmente. Assim, médicos têm habitus e estilo de vida afins, que vão provocar açóes práticas semelhantes. Desse modo, ao estudar as competências médicas dos participantes, estamos tentando captar o habitus relacionado ao estilo de vida médica dentro de sua posição de classe.

Considerando o conjunto de saberes e práticas de um determinado grupo social (médicos) acerca dos transtornos mentais e consumo de drogas, seria possível identificar interferência do habitus na produção de cuidado de saúde dessa população?

\section{O método}

Este trabalho enfocou a questão da barreira de acesso à saúde, buscando identificar, com recursos da pesquisa qualitativa, competências médicas marcadas pelo estigma que possam influenciar negativamente na relação médico-usuário.

Antes de tudo, é importante ressaltar que o objeto de pesquisa nas ciências sociais é incontestavelmente histórico. Ainda mais, considera indivíduos e coletivos detentores de mecanismos de consciência da realidade histórica e de capacidade para interpretá-los e transformá-los. Investigador e sujeito de pesquisa encontramse unidos por laços sociais que devem ser levados em conta na produção de conhecimentos (MINAYO, 2014).

O pesquisador e os participantes da pesquisa possuem graduação em medicina e atuam dentro de um mesmo território, embora com atribuiçóes distintas (o primeiro como especialista e esses como médicos da estratégia de saúde da família), mas encontrando interseção no cuidado da população com transtornos mentais. Isso facilitou a aproximação do investigador aos sujeitos estudados e a compreensão do modo de pensar atribuído à formação médica.

A maior experiência (e a formação especializada) do pesquisador com a área da psiquiatria, por distingui-lo dos sujeitos de pesquisa, possibilitou a observação distante das competências relacionadas com o objetivo da pesquisa dos médicos não-psiquiatras. Dessa maneira, todo o processo de formação daquele que investiga influenciou na forma como enxerga a atuação dos participantes nessa área em 
que é especialista. Como fluxo da relação pesquisador-sujeito de pesquisa, os não especializados na saúde mental também produzem elementos próprios sobre o objeto de estudo, sendo capazes de fazer interpretaçôes.

Nas pesquisas sociais de forma geral, mais comumente aplicados entre participantes leigos, esses elementos são conhecidos como senso comum, expresso "na forma pela qual os seres humanos chegam ao sentido da realidade objetiva" (MINAYO, 2014, p.150). Minayo (2014, p.41) os chama de "primeiro nível” de interpretação, sendo conteúdo para a análise da pesquisa quando questionado criticamente.

No caso deste trabalho, não podemos afirmar que os participantes sejam leigos, já que são médicos e esperava-se que a formação garantiria um conjunto de competências, distanciando os sujeitos da posição de imperitos. Dessa forma, por aproximação analógica, ampliamos a ideia de senso comum para a de habitus - primário (quando se referindo ao senso comum proveniente da cultura de uma forma geral) e secundário (quando se considerou a transformação do senso comum pela formação médica).

Conforme Bourdieu (2007, p.164), "a experiência comum do mundo social" é o "reconhecimento de uma ordem" que já estava estabelecida anteriormente na memória. No caso do habitus secundário, pode-se considerar a existência de uma experiência comum à classe médica, sendo a formação um meio para o reconhecimento de tal ordem "gravada no cérebro".

Roy Turner (1974, p.205) faz reflexôes acerca da linguagem como limites da pesquisa sociológica. Ele defende que a comunicação oral tem um papel que vai além da simples comunicação, tendo ainda uma função de ação - "fazer coisas com palavras". Argumenta que, para o estudo sociológico, a fala não deve ser tomada como tendo a função apenas de reportar uma forma de agir. Isso exige uma metodologia capaz de analisar trechos de conversas tendo em vista o poder de açáo das palavras.

Turner (1974) defende ainda que o sociólogo deve colocar como questionamento a forma como a comunicação verbal se evidencia enquanto atividade unitária reconhecível. Isso requer que o autor explique os recursos que ele compartilha com os sujeitos pesquisados e que fazem dar sentido à comunicação analisada no trecho de uma conversa. No caso deste estudo, a formação médica é o elo que legitima a busca e a interpretação do habitus dos participantes pelo pesquisador.

Goffman (2008), referência canônica no estudo do estigma, revela a interação entre os símbolos e as relaçôes sociais e o reflexo da maneira de pensar sobre o modo de agir, concepções que também apoiam a interpretação dos achados deste estudo. 
Neste artigo, a observação participante consiste no procedimento metodológico central da investigação, sendo aplicado nas atividades de matriciamento e na estratégia educativa. Considerando que as palavras são dotadas de ação, a detecção de estigmas nos discursos dos médicos da atenção básica indica provável interferência deles na prática de cuidado. A emergência desse conteúdo é também, sob o aspecto pedagógico, uma oportunidade para reconstruir conceitos e, quem sabe, a práxis.

Após aprovação do Comitê de Ética em Pesquisa do IPUB/UFRJ, pelo parecer número 1.988.933, a observação do matriciamento com anotaçôes teve início em novembro de 2016, finalizando em dezembro de 2017. Neste artigo apresentaremos os resultados da estratégia educativa que ocorreu no final desse período e foi gravada em áudio com consentimento dos participantes e transcrita para análise.

\section{A observação da estratégia educativa}

A aula foi aplicada como atividade de matriciamento e foi útil para a observação mais acurada das competências profissionais. O presente trabalho não se preocupa diretamente com a avaliação dos efeitos da estratégia educativa.

\section{O método de Paulo Freire nesta pesquisa}

$\mathrm{Na}$ busca de alinhar o habitus com as teorias do processo formativo, a pedagogia de Freire trouxe importante contribuição. A prática educativa freiriana dá suporte ao método pedagógico utilizado por reunir particularidades interessantes ao estudo. Seu método parte invariavelmente da realidade dos educandos e educadores, buscando compreender contextos históricos e relaçóes sociais, culturais e de classe. Um método que pretenda abordar o estigma como objeto de aprendizagem não pode deixar de considerar esses aspectos.

As obras de Freire ensinam que educação é uma forma de intervir no mundo, que o ato de refletir não fica estancado na mera reflexão, mas se estende para a ação, com potencialidade de transformar as relaçôes de poder (FREIRE, 1987).

Para o matriciamento engajado com a inserção social do louco, o método pedagógico deve provocar a práxis, tensionando reflexáo acerca da realidade de trabalho. Apenas a reflexão sobre a ação é capaz de transformar a própria ação e, assim, o mundo. Os autores desta pesquisa apostaram nesse método pedagógico por acreditarem na problematização da realidade social e política como caminho para transformação das atitudes relacionadas ao estigma. 
O matriciamento é uma ferramenta técnico-pedagógica potente e permite que os profissionais reflitam sobre casos e temas que fazem parte do seu fazer, no local onde fazem. Considerando que, para Freire (1996), o ensinamento técnico não pode ser dissociado da formação ética, a prática do matriciamento não pode se eximir de seu caráter ético de construir uma prática de saúde com respeito à dignidade humana.

No livro Educação e Mudança, Freire (1979) circunscreve seu método para uma sociedade em transformação. Argumenta que uma época histórica é formada por um conjunto de valores que buscam a plenitude, mas enquanto são envolvidos pelo homem, inacabado e consciente de seu inacabamento, a sociedade está em constante mudança. Para que essa transformaçáo seja desempenhada com criticidade e possibilite a transformação da realidade em busca de superar a via dominante, Freire aponta propriedades do método educativo: ele deve ser ativo, crítico e dialogal.

\section{A aplicação da estratégia}

A estratégia pedagógica foi sendo amadurecida no caminho de buscar uma forma de captar o estigma nos conceitos e na experiência prática dos médicos com a população com transtornos mentais.

Para Freire (1987), o processo de aprendizagem exige colocar em evidência os saberes prévios (o habitus, segundo Bourdieu) e as experiências com a realidade de estudantes e professor, material que, quando posto em reflexão crítica, é capaz de gerar aprendizagens bilateralmente e, como consequência, espera-se também a transformação da práxis.

Em diálogo com o supervisor local do PMM, para averiguar as necessidades pedagógicas do público-alvo, decidiu-se pela realização de uma aula, com método ativo de ensino, com o tema: "Cuidado em saúde mental na atenção primária”. Esse tema satisfez as necessidades dos médicos para sua formação e foi útil aos interesses do trabalho. Os procedimentos pedagógicos foram planejados para permitir livremente o aparecimento dos saberes sobre transtornos mentais (conhecimento), das maneiras como os médicos agem (habilidades e atitudes) e o que sentem (atitudes) quando diante de casos ou situaçóes de saúde mental.

O objetivo geral da aula foi apresentado como sendo problematizar o cuidado em saúde mental na atenção primária e todos os participantes sabiam - e assinaram TCLE - que a aula fazia parte de uma pesquisa que estudava estratégias de ensino para superar o estigma à população com transtornos mentais. 
Classificamos as competências em conceitos, habilidades e atitudes de acordo com as Diretrizes Curriculares Nacionais para o curso de medicina de 2014, visando a um estudo pedagógico baseado nas competências (BRASIL, 2014). A construção da aula teve como referência a Matriz de Correspondência Curricular para Fins de Revalidação de Diplomas de Médico Obtidos no Exterior - REVALIDA (BRASIL, 2009), por ser um documento federal oficial no qual consta o perfil de competências exigido para os médicos atuantes no Brasil.

A expectativa do pesquisador era a de observar o conteúdo trazido pelos médicos em relação a como o estigma se evidencia: a) nos conceitos que os médicos carregam em relação ao transtorno mental e ao consumo de drogas, b) na forma como conduzem o cuidado das pessoas com esses transtornos, e c) na relação estabelecida entre o médico e essa população. Interessa ainda saber como o habitus aparece nesse contexto. Para captação dessas informaçôes foi utilizado o roteiro para a observação de campo (Quadro 1).

\section{Quadro 1. Roteiro de Observação Participante}

\begin{tabular}{|c|c|c|c|}
\hline Contexto & Conceitos & Habilidades & Atitudes \\
\hline $\begin{array}{l}\text { Perguntas norteadoras: } \\
\text { Que elementos do } \\
\text { território são citados } \\
\text { pelos médicos como } \\
\text { facilitador ou entrave ao } \\
\text { cuidado? } \\
\text { Que relação o } \\
\text { médico estabelece } \\
\text { com a atividade } \\
\text { de matriciamento? } \\
\text { (É interessado ou } \\
\text { náo, entende como } \\
\text { apoio e cogestão ou } \\
\text { como atendimento } \\
\text { especializado, prefere } \\
\text { encaminhar ao } \\
\text { ambulatório) }\end{array}$ & $\begin{array}{l}\text { Perguntas norteadoras: } \\
\text { Que conceitos são } \\
\text { usados por médicos } \\
\text { para identificar os } \\
\text { usuários como tendo } \\
\text { transtorno mental/ } \\
\text { uso problemático de } \\
\text { substâncias? } \\
\text { Há conceitos que } \\
\text { relacionam de forma } \\
\text { indiscriminada esses } \\
\text { usuários com violência, } \\
\text { incapacidade para o } \\
\text { trabalho, desesperança } \\
\text { de recuperação, } \\
\text { problemas de relaçóes } \\
\text { interpessoais, } \\
\text { impossibilidade de } \\
\text { viver em comunidade, } \\
\text { tráfico de drogas } \\
\text { ou outros conceitos } \\
\text { estigmatizadores? }\end{array}$ & $\begin{array}{l}\text { Perguntas norteadoras: } \\
\text { Na condução dos } \\
\text { casos, existem açóes } \\
\text { que denotam estigma, } \\
\text { como recusa/ resistência } \\
\text { a atendimento, } \\
\text { negligência de } \\
\text { queixas psíquicas, } \\
\text { desvalorizaçáo de } \\
\text { situaçóes clínicas, } \\
\text { condução inadequada } \\
\text { das consultas ou outros? } \\
\text { Há tendência a } \\
\text { encaminhamentos } \\
\text { para tratamentos } \\
\text { em Hospitais ou } \\
\text { comunidades } \\
\text { terapêuticas (sem } \\
\text { relação com indicação } \\
\text { clínica)? }\end{array}$ & $\begin{array}{l}\text { Perguntas norteadoras: } \\
\text { Como é a postura } \\
\text { do médico quando } \\
\text { em contato com (ou } \\
\text { quando discute sobre) } \\
\text { o usuário da saúde } \\
\text { mental? (interessado, } \\
\text { profissional } \\
\text { com tendência } \\
\text { a neutralidade, } \\
\text { desinteressado, } \\
\text { resistente, avesso/ } \\
\text { evitativo?) } \\
\text { Que elementos da } \\
\text { abordagem do médico } \\
\text { tendem a aproximar } \\
\text { ou afastar o usuário do } \\
\text { cuidado? }\end{array}$ \\
\hline
\end{tabular}

Fonte: os autores 
Para a estratégia da pesquisa, com intenção de observar o estigma e o habitus, o pesquisador decidiu abordar na aula três aspectos gerais da atenção às pessoas com transtornos mentais e consumo de drogas: 1) conhecimentos - conceito de transtorno mental, uso/abuso/dependência de substâncias, modelos de atenção à saúde mental; 2) habilidades - identificação de casos da saúde mental (diagnóstico em psiquiatria), gestão do cuidado dessa população (o papel da atenção primária) e 3) atitudes sentimentos contra-transferenciais e estigma como interferência no cuidado.

O plano de aula foi constituído de estratégia de ensino dividida em duas partes e se aproximou de aulas do tipo grupos de murmúrio (buzzgroups) (LOPES; LOPES, 2012). A amostra foi constituída pelos médicos do PMM - 6 médicos da ESF e 2 supervisores locais do Programa.

É importante destacar que, no uso dos métodos ativos de ensino, nem sempre é possível manter a aula dentro do planejamento, pois a dinâmica do grupo dentro do processo pedagógico pode levar a diversos caminhos. O facilitador deve esforçar-se para manter a discussão dentro do objetivo proposto, porém deve ter flexibilidade para seguir caminhos que o grupo decide tomar (LOPES; LOPES, 2012).

\section{Primeira parte da aula}

A primeira parte da aula consistia em apresentação breve dos participantes e do projeto de pesquisa e da aula; divisão dos 8 participantes em 2 subgrupos, com 4 pessoas. Por escolha do grupo, cada subgrupo manteve a estrutura de divisáo da supervisão, entáo cada supervisor participou junto de seus supervisionados e viceversa. Isso parece ter tido importância para esta primeira parte da aula, que não foi gravada, apenas anotada em diário de campo.

Essa etapa tinha como objetivo preparar o grupo, fazendo-os entrar em contato com suas experiências reais. Além disso, era um caminho para fazer emergirem as competências prévias dos participantes acerca do tema proposto.

Divididos em dois grupos, receberam instruçôes para pensar casos envolvendo saúde mental no seu território. Em seguida deviam compartilhar brevemente os casos no subgrupo e escolher um deles para aprofundar a discussão - que foi subsidiada com roteiro de discussão entregue aos participantes.

Sem interferência do pesquisador, algumas situações da prática foram discutidas entre médicos e supervisores do Programa. Houve momentos de 
acaloramento das discussóes, incluindo ocasião em que um dos participantes chorou ao relatar uma experiência.

Esse primeiro exercício "aqueceu" os participantes para a aula. A ideia de usar casos clínicos da realidade os deixou à vontade para falar de suas experiências e de suas emoções nessas experiências.

\section{Segunda parte da aula}

A segunda etapa da aula começou pela exposição dos participantes de como foi a discussão nos subgrupos: os dois subgrupos afirmaram ter discutido casos em geral e decidiram levantar para a discussão questôes mais coletivas ao invés de um caso individual, como sugerido na demanda da aula. Um dos subgrupos discutiu o problema do uso de benzodiazepínicos nos territórios e o outro, o uso de drogas lícitas e ilícitas. O debate, porém, não se limitou a esses assuntos, levantando conteúdos gerais relacionados à saúde mental.

Para continuidade, o plano previa que cada subgrupo relatasse a discussão dos casos referente às perguntas do eixo $\mathrm{A}$ (identificação do transtorno mental ou do problema decorrente do uso de drogas), que seria seguido da explanação do facilitador (o pesquisador) com pranchas sobre: conceito de transtorno mental, conceito de uso/ abuso/dependência de substâncias e as principais síndromes psíquicas.

Seguia-se, então, para as perguntas do eixo B (condução do cuidado/ assistência na atenção primária), com planos para que o facilitador apresentasse conteúdos sobre a Rede de Atenção Psicossocial, aspectos da saúde mental na atenção primária e princípios gerais da prescrição de psicotrópicos.

Após exposição pelos participantes de sua discussão sobre o eixo C (relação médico-paciente/ sentimentos do médico), o facilitador apresentou slides sobre o estigma como barreira de acesso e discutiu os sentimentos contra transferenciais na relação médico-usuário.

\section{Sistematização e análise dos dados}

O material gravado da segunda parte da aula foi transcrito e a primeira análise do material consistiu em leitura da transcrição em busca de verificar as competências pedagógica dos médicos relacionadas à saúde mental - o que demonstraram saber (conceitos), fazer (habilidades) e ser/sentir (atitudes). Após leitura, o conteúdo foi dividido de acordo com as competências em quadros de análise por competência: 
conceitos, habilidades e atitudes. Também foi separado qualquer material que tivesse relação com o contexto do trabalho na ESF (incluindo o matriciamento), do território e da formação médica. Assim, a análise posterior seguiu a divisão por esses 4 pilares: 1) contexto, 2) conceitos, 3) habilidades e 4) atitudes. Essa classificação é apenas metodológica e muitas vezes há intersecçôes entre os pilares.

O quadro de análise do Pilar 1(contexto) conteve duas colunas: a primeira com a fala do participante e a segunda para primeira observação de análise. No caso das competências pedagógicas, 3 colunas foram necessárias: uma para a citação do participante, outra para especificar se a competência tinha ou não relação com o estigma e outra para a primeira observação de análise, incluindo análise de se o habitus envolvido era primário ou se tinha influência da formação médica (habitus secundário).

Em seguida foi realizada uma segunda análise com identificação dos elementos de fórmula proposta por Turner (1974) para estudar trechos de conversa: [sujeito da fala/ação] + [verbo da ação] + [complemento], com intuito de apontar para a presença de estigmas entre as competências. Neste trabalho, com finalidade metodológica, seria possível pensar essa fórmula da seguinte maneira: [médico(a) da atenção básica] + [verbo correspondente à competência em questão - saber, fazer, sentir/ser] + [complemento cujo juízo de valor sinalize estigma e habitus].

A transcrição de conversas e sua disposição em fórmulas permitiria a identificação de itens enquanto instâncias de ações. Turner enfatiza que a simples correspondência semântica e sintática das palavras não é suficiente para uma análise de discursos associados às açôes. É importante uma compreensão do contexto, pois os sentidos das palavras podem variar de acordo com quem é que fala, qual a forma (entonaçóes, por exemplo) de dizê-las e o contexto cultural em que comunicador e ouvinte estão inseridos.

A seguir, mostraremos o resultado em quadro organizado por competências após a segunda análise.

\section{Resultados e Discussão}

Apresentaremos os resultados referentes aos pilares das competências: conceitos, habilidades e atitudes. O quadro 2 - Resultados - compila os resultados encontrados mais importantes para cada competência, trazendo uma coluna com a citação do(a) médico(a) sujeito da pesquisa. 
Nas citaçôes, marcamos em negrito os verbos que auxiliaram na classificação de qual tipo de competência apresentada. Na terceira coluna aponta-se qual o estigma identificado a partir da análise da citação. $\mathrm{Na}$ última coluna do quadro 2, classificou-se o habitus predominante: se primário ou habitus interferido pela formação médica (secundário).

\section{Quadro 2. Resultados}

\begin{tabular}{|c|c|c|c|}
\hline \multirow{2}{*}{ 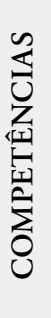 } & \multicolumn{3}{|c|}{$\begin{array}{l}\text { Identificação de estigmas } \\
\text { co(a) da atenção básica com suas singularidades }]+ \text { [verbo } \\
+ \text { [complemento cujo juízo de valor sinalize estigma e habitus } \\
\text { predominante] }\end{array}$} \\
\hline & $\begin{array}{c}\text { FALA DESTACADA DO (A) } \\
\text { MÉDICO (A) }\end{array}$ & SINAIS DE ESTIGMA & $\begin{array}{c}\text { ELEMENTOS DO } \\
\text { HABITUS }\end{array}$ \\
\hline \multirow{3}{*}{ 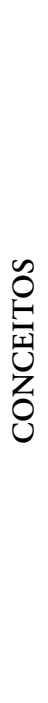 } & $\begin{array}{l}\text { Eu acho o paciente da } \\
\text { saúde mental tem isso como } \\
\text { característica: é o paciente } \\
\text { recorrente, que te desafia como } \\
\text { profissional. }\end{array}$ & $\begin{array}{l}\text { Generalização: "o paciente } \\
\text { como recorrente, desafiador". }\end{array}$ & $\begin{array}{l}\text { Habitus secundário - conceito } \\
\text { relacionado ao cuidado em } \\
\text { saúde }\end{array}$ \\
\hline & $\begin{array}{l}\text { Nem vem com desculpa de } \\
\text { fumante, porque conheço } \\
\text { todas (...); entáo os meus } \\
\text { grupos de tratamento pra } \\
\text { tabagistas funciona, porque } \\
\text { mentir pra mim fica difícil. }\end{array}$ & $\begin{array}{l}\text { Minimização: sintomas } \\
\text { relacionados ao consumo de } \\
\text { drogas como desculpas. }\end{array}$ & $\begin{array}{l}\text { Habitus primários se sobrepõe } \\
\text { ao secundário (conceito } \\
\text { aproxima-se do conceito } \\
\text { esperado para um leigo) }\end{array}$ \\
\hline & $\begin{array}{l}\text { A sua relação com a doença, } \\
\text { com o transtorno mental, com } \\
\text { a psiquiatria depois enquanto } \\
\text { médico vai depender muito da } \\
\text { sua bagagem (do que sabe). }\end{array}$ & $\begin{array}{l}\text { Reducionismo da pessoa para } \\
\text { a doença. }\end{array}$ & $\begin{array}{l}\text { Habitus secundário - modelo } \\
\text { de cuidado reducionista }\end{array}$ \\
\hline
\end{tabular}

continua... 


\begin{tabular}{|c|c|c|c|}
\hline \multirow{2}{*}{ 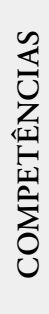 } & \multicolumn{3}{|c|}{ Identificação de estigmas } \\
\hline & $\begin{array}{c}\text { FALA DESTACADA DO (A) } \\
\text { MÉDICO (A) }\end{array}$ & SINAIS DE ESTIGMA & $\begin{array}{c}\text { ELEMENTOS DO } \\
\text { HABITUS }\end{array}$ \\
\hline \multirow{5}{*}{ 全 } & $\begin{array}{l}\text { O paciente que sempre vai } \\
\text { voltar para você... dependendo } \\
\text { de como você abordar ele, vai } \\
\text { ficar dependente de você. }\end{array}$ & $\begin{array}{l}\text { Generalização do paciente } \\
\text { como dependente. }\end{array}$ & $\begin{array}{l}\text { Habitus secundário - } \\
\text { habilidade relacionado ao } \\
\text { cuidado em saúde }\end{array}$ \\
\hline & $\begin{array}{l}\text { Não tem como você fazer esse } \\
\text { homem se superar, não existe, } \\
\text { não existe mais essa opção. }\end{array}$ & $\begin{array}{l}\text { Desesperança quanto a } \\
\text { recuperaçáo }\end{array}$ & $\begin{array}{l}\text { Habitus secundário: parece } \\
\text { se relacionar com inabilidade } \\
\text { médica para lidar com a } \\
\text { situação }\end{array}$ \\
\hline & $\begin{array}{l}\text { Se eu vejo por exemplo uma } \\
\text { alteração do senso crítico, } \\
\text { o paciente chega com um } \\
\text { discurso confuso, um discurso } \\
\text { religioso, um discurso com } \\
\text { grande eloquência, (...) aí isso } \\
\text { não é mais comigo não, eu } \\
\text { mando para o psiquiatra. }\end{array}$ & Desresponsabilização & $\begin{array}{l}\text { Habitus secundário - } \\
\text { inabilidade médica e relação } \\
\text { com modelo de cuidado } \\
\text { reducionista. }\end{array}$ \\
\hline & $\begin{array}{l}\text { Dos outros, chega uma cólica, } \\
\text { você dá um analgésico e } \\
\text { pronto! Ah eu sou a médica! } \\
\text { Eu sou a superpoderosa. } \\
\text { Resolvi o problema! Mas com } \\
\text { saúde mental, é } \\
\text { muito diferente... (não sei } \\
\text { resolver) }\end{array}$ & $\begin{array}{l}\text { Ideia de ausência, de } \\
\text { perspectiva de ação médica, } \\
\text { incurabilidade. }\end{array}$ & $\begin{array}{l}\text { Habitus secundário - refere-se } \\
\text { diretamente à atuação médica }\end{array}$ \\
\hline & $\begin{array}{l}\text { Os pacientes têm uma situação } \\
\text { social ao redor e você sente: } \\
\text { caraca, bicho, eu não consigo } \\
\text { resolver isso daqui! O que é } \\
\text { que eu vou fazer? }\end{array}$ & $\begin{array}{l}\text { Sentimento de incapacidade e } \\
\text { tendência a reduçáo da questão } \\
\text { à “situação social”. }\end{array}$ & $\begin{array}{l}\text { Habitus secundário - } \\
\text { inabilidade médica para cuidar } \\
\text { em situaçóes complexas }\end{array}$ \\
\hline
\end{tabular}

continua... 


\begin{tabular}{|c|c|c|c|}
\hline \multirow{2}{*}{ 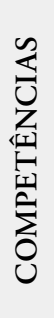 } & \multicolumn{3}{|c|}{$\begin{array}{l}\text { Identificação de estigmas } \\
\text { co(a) da atenção básica com suas singularidades] + [verbo } \\
+ \text { [complemento cujo juízo de valor sinalize estigma e habitus } \\
\text { predominante] }\end{array}$} \\
\hline & $\begin{array}{c}\text { FALA DESTACADA DO (A) } \\
\text { MÉDICO (A) }\end{array}$ & SINAIS DE ESTIGMA & $\begin{array}{c}\text { ELEMENTOS DO } \\
\text { HABITUS }\end{array}$ \\
\hline \multirow{5}{*}{  } & $\begin{array}{l}\text { "Por que assim, é um } \\
\text { paciente que te frustra como } \\
\text { profissional. }\end{array}$ & $\begin{array}{l}\text { Sentimento negativo } \\
\text { generalizado. }\end{array}$ & $\begin{array}{l}\text { Habitus secundário - } \\
\text { relacionado com modelos de } \\
\text { cuidado e cura }\end{array}$ \\
\hline & $\begin{array}{l}\text { Por exemplo o alcoolista, } \\
\text { tipo você vai fazer o } \\
\text { acompanhamento, vai passar } \\
\text { um tempáo ouvindo ele e pode } \\
\text { ser que ele tenha uma recaída } \\
\text { e você vai dizer: cara que } \\
\text { merda! Eu sou uma droga de } \\
\text { profissional! }\end{array}$ & $\begin{array}{l}\text { Sentimento negativo de } \\
\text { frustração }\end{array}$ & $\begin{array}{l}\text { Habitus primário parece } \\
\text { predominar em relaçáo } \\
\text { ao cuidado relacionado às } \\
\text { dependências }\end{array}$ \\
\hline & $\begin{array}{l}\text { É você ser afetado, tudo que } \\
\text { afeta a gente, faz com que a } \\
\text { gente demore a absorver, para } \\
\text { depois daí fazer a ação. }\end{array}$ & $\begin{array}{l}\text { Sentimentos que interferem } \\
\text { em açóes }\end{array}$ & $\begin{array}{l}\text { Habitus primário - sentimentos } \\
\text { inerentes à humanidade } \\
\text { interferindo nas açóes. }\end{array}$ \\
\hline & $\begin{array}{l}\text { A gente também de certa } \\
\text { forma estigmatiza um pouco, } \\
\text { porque a gente se sente } \\
\text { incapaz. Quando a gente se } \\
\text { sente um pouco mais capaz, a } \\
\text { gente consegue conduzir pelo } \\
\text { menos alguns casos. }\end{array}$ & $\begin{array}{l}\text { Relato direto de estigma } \\
\text { associado ao sentimento de } \\
\text { incapacidade. }\end{array}$ & $\begin{array}{l}\text { Habitus primário } \\
\text { predominante sobre formação } \\
\text { médica insuficiente. }\end{array}$ \\
\hline & $\begin{array}{l}\text { Não me diga o que ele fez. } \\
\text { Porque eu percebi em uma das } \\
\text { pacientes que eu tinha raiva. } \\
\text { Então eu tentava ser objetiva } \\
\text { em dar o tratamento médico } \\
\text { correto pra ele, mas eu sabia } \\
\text { que a relação era prejudicada } \\
\text { pelo fato de já julgar o que } \\
\text { ele fez. }\end{array}$ & $\begin{array}{l}\text { Sentimento de raiva } \\
\text { interferindo em açóes. }\end{array}$ & $\begin{array}{l}\text { Habitus primário - sentimentos } \\
\text { inerentes à humanidade } \\
\text { interferindo nas açôes. }\end{array}$ \\
\hline
\end{tabular}

Fonte: os autores 
Os resultados revelaram nas competências médicas aspectos implícitos das marcas do estigma relativo aos transtornos mentais. Esse reconhecimento está alinhado com a ausência do desenvolvimento da competência cultural e sua repercussão na prática clínica.

O desenvolvimento dessa competência está relacionado com colocar em evidência aspectos inconscientes, levando ao reconhecimento dos desafios de lidar com o diferente, da incerteza como uma característica da prática clínica e das relações que se estabelecem entre diferentes grupos sociais na produção do cuidado em saúde (KIRMAYER, 2013).

As marcas de estigmas identificadas nas competências dos médicos participantes - generalizaçôes, minimizaçôes, reducionismos, desesperanças quanto à recuperação e sentimentos negativos - são ideias conhecidas associadas ao transtorno mental e estão relatadas nos estudos consultados sobre o tema da estigmatização exercida por profissionais de saúde (THORNICROFT, 2006)

\section{O que a análise do habitus revela?}

Nas competências relacionadas aos conceitos e às habilidades, pode-se perceber interferência da formação (habitus secundário), revelando um "ser médico" com predomínio do pensamento biomédico e fragmentado, que ora reduz o transtorno mental a uma entidade patológica que seria de competência do saber psiquiátrico (especializado), ora a uma questão social (que não seria da competência médica). Isso revela uma inabilidade com as situaçôes de saúde mental e social. Um dos participantes justificou diretamente seus estigmas com o seu sentimento de incapacidade.

Saber pouco sobre o núcleo da psiquiatria também foi relacionado com os sentimentos de insegurança. Essa dificuldade tem relação direta com a preparação médica para o fazer que envolve o circuito diagnóstico-tratamento. Se não é possível estabelecer diagnóstico, o médico pode se sentir perdido para conduzir uma situação de encontro clínico.

O habitus secundário relacionado à capacidade de fazer diagnósticos parece trazer uma falsa ideia de resolver a dificuldade relacional. É fundamental discordar dessa ideia ou estaríamos afirmando que um bom conhecimento de psicopatologia resolveria o problema do estigma. Ao contrário, Thornicroft (2006, p.1439,1463,1467) traz dados que colocam o psiquiatra como um dos atores sociais que têm ideias negativas acerca de seus pacientes. E se assim fosse, um leigo não 
teria condiçóes de se relacionar bem com alguém que tenha transtorno mental, o que não é verdade. Parece, portanto, haver falhas na formação de habilidades de comunicação em busca de atitudes respeitosas.

A ideia da perda do senso crítico parece ter relação com habitus primário e secundário. Primário pela ideia social de que o louco é aquele que está fora de si, não tem controle e não responde por si. A formação médica consolida essa ideia, que toma um caráter científico com nome técnico de perda de autonomia e da crítica. Obviamente, existem situações psiquiátricas em que essas perdas ocorrem, mas geralmente são relativas e adaptáveis à rotina da pessoa; a generalização dessa ideia para todas as pessoas com transtornos mentais e para todas as situaçôes corresponde ao processo de estigmatização.

Quando o tema debatido foi álcool e outras drogas (AD), o habitus primário prevaleceu; vale destacar o uso de linguagem coloquial ("alcoolista", "desculpa de fumante") ao invés de terminologias como "doença" e "senso crítico", sugerindo pouca (ou nenhuma) interferência da formação médica no campo do AD. Andrade (2011) aponta sérias dificuldades para o atendimento dessa clientela na atenção básica.

Para as competências atitudinais, o habitus primário também foi predominante, os sentimentos negativos foram unânimes e indicavam influência maior do senso comum, levando a crer que as estratégias de formação não atingem a transformação de sentimentos e atitudes relacionados aos transtornos mentais.

\section{Considerações Finais}

A observação participante das atividades de matriciamento na atenção básica colocou o pesquisador em posição privilegiada para identificar competências médicas relacionadas com o estigma. A utilização de casos reais como facilitador do processo de ensino-aprendizagem contribuiu com a metodologia, revelando um habitus marcado pela biomedicina e o cuidado fragmentado com tendência a transferir o cuidado em saúde mental para o especialista.

Admitida a existência de estigma interferindo em açóes do médico, o ensino deve se preocupar com a superação desse problema. A análise dos sinais de estigma em conceitos e habilidades parece confluir para elementos que fazem parte do componente atitudinal (sentir e ser), relacionado à competência cultural, levando a acreditar que as estratégias de enfrentamento ao estigma devem propor métodos que atinjam essa competência. 
Devido aos aspectos metodológicos, este estudo não pode ser generalizado para outros contextos, mas os dados levantados podem contribuir para o estudo do tema e para a tomada de decisão acerca de políticas de educação permanente de saúde e diretrizes curriculares com objetivo de superar o estigma como barreira de acesso aos serviços de saúde.

A pesquisa não teve financiamento e os autores declaram não ter nenhum conflito de interesses.

\section{Referências}

ANDRADE, TM. Reflexóes sobre políticas de drogas no Brasil. Ciência \& Saúde Coletiva, v16, p. 4665-4674, 2011.

BOURDIEU, P. A economia das trocas simbólicas. 6. Ed. São Paulo: Perspectiva, 2007.

A distinção: crítica social do julgamento. São Paulo: Edusp; Porto Alegre, RS:

Zouk, 2007.

BRASIL. Presidência da República. Lei no 12.871, de 22 de outubro de 2013b. Institui o Programa Mais Médicos, altera as Leis no 8.745, de 9 de dezembro de 1993, e no 6.932, de 7 de julho de 1981, e dá outras providências (Online). Brasília, DF; 2013. Disponível em: http:// www.planalto.gov.br/ccivil_03/_ato2011-2014/2013/Lei/L12871.htm (Acesso em 19/02/2019).

$10 / 05 / 2016$.

IBGE. Censo demográfico, 2010. Disponível em www.ibge.gov.br Acesso em

Ministério da Educação. Conselho Nacional de Educação. Câmara de Educação Superior. Resolução CNE/CES no3 de 20 de junho de 2014. Institui diretrizes curriculares nacionais do curso de graduação em Medicina e dá outras providências. Diário Oficial da União. Brasília, 6 jun. 2014. Acesso em 14 de março de 2017.

Ministério da Educação. Secretaria de Ensino Superior. Ministério da Saúde. Secretaria da Gestão do Trabalho e Educação na Saúde. Matriz de correspondência curricular para fins de revalidação de diplomas de médico obtidos no exterior / Ministério da Educação, Ministério da Saúde. - Brasília: MEC, MS, 2009. 69p. Vários autores.

FLEXNER, A. Medical Education in the United States and Canada. New York: Carnegie Foundation for The Advancement of Teaching; 1910.

FREIRE, P. Pedagogia do Oprimido. $17^{\mathrm{a}}$ ed. Rio de Janeiro, Paz e terra, 1987. Pedagogia da autonomia - saberes necessários à prática educativa. $1^{a}$ ed. São Paulo: Paz e Terra, 1996. 
Educação e mudança. 22a ed.; tradução de Moacir Gadotti e Lillian Lopes Martin. Rio de Janeiro: Paz e Terra. 1979.

GOFFMAN, E. Estigma: notas sobre a manipulação da identidade deteriorada. 4o edição. Rio de Janeiro, LTC, 2008.

IPEA - INSTITUTO DE PESQUISA ECONÔMICA APLICADA. Atlas da violência, 2013. <https://www.ipea.gov.br/atlasviolencia/dados-series/20> Acesso em 29 de jul. de 2020.

KIRMAYER, LJ. Rethinking cultural competence. Transcultural Psychiatry, v49, n2, p. 149$164,2012$.

Embracing uncertainty as a path to competence: Cultural safety, empathy, and alterity in clinical training. Culture, Medicine, and Psychiatry, v37, n2, p.365-372, 2013.

LOPES, M. H. I.; LOPES, J. M. C. Metodologias de ensino médico. In: GUSSO, G. D. F., LOPES, J. M. C. (Org.) Tratado de Medicina de Família e Comunidade-Princípios, Formação e Prática. Porto Alegre: ARTMED, 2012, p365-373.

LUZ, M. Natural, racional, social: razão médica e racionalidade científica moderna. 3.Ed. São Paulo: HUCITEC Editora, 2012.

MATTOSO, A. Ipojuca: passado, presente, futuro do Municipio que mais cresce em Pernambuco, Recife. Carpe Diem Ediçôes e Produções, 2013. 84p.

MINAYO, M. C. S. O desafio do conhecimento-pesquisa qualitativa em saúde. 14.Ed. São Paulo: HUCITEC Editora, 2014.

MOURA, A.C. A. et al. Estratégias de Ensino-Aprendizagem para Formação Humanista, Crítica, Reflexiva e Ética na Graduação Médica: Revisão Sistemática. Rev. bras. educ. med., Brasília, v44, n3, e076, 2020 .

NUNES, M.; TORRENTE, M. Estigma e violências no trato com a loucura: narrativas de centros de atenção psicossocial, Bahia e Sergipe. Rev. Saúde Pública, São Paulo, v43, supl1, p.101-108, 2009.

PEGORARO, R. F.; CASSIMIRO, T. J. L.; LEAO, N. C. Matriciamento em saúde mental segundo profissionais da Estratégia de Saúde da Família. Psicol. estud., Maringá, v19, n4, p.621631. 2014.

RÉZIO, L. A. et al. Contribuições do PET-Saúde/Redes de Atenção Psicossocial à Saúde da Família. Interface - Comunicação, Saúde, Educação [online]. 2015, v19, suppl1, pp.793-803.

THORNICROFT, G. Shunned: discrimination against people with mental illness. 1.Ed. New York: Oxford University Press Inc.,2006. 4399p[e-book].

TURNER, R. Words, utterances and activities. In: Turner, R(ed.) Ethnomethodology. Middlesex, Penguin Books, 1974. 


\section{Abstract}

Stigma and mental health in primary care:

can gap in medical education interfer in access to health?

This article aims to identify medical competencies marked by stigma against people with mental disorders. We analyzed, based on Pierre Bourdieu's concept of habitus, the interference of medical training in the thinking and action of primary care doctors to manage cases of people with those disorders. This research used features of participant observation on a lesson applied by a psychiatrist for primary care physicians in matrix support activities. We describe the pedagogical strategy developed that, when analyzed, was able to demonstrate stigmas in the competencies of doctors, with a potential negative consequence for healthcare, like generalizations, reductionisms, hopelessness and other feelings associated with barriers to access to care giving of that population.

Keywords: Social stigma and mental health, mental health and primary care, medical anthropology, medical education, primary health care. 